\title{
The Function of Organic Additives in Enhancing the Q-values for Peat Pellet Biofuel
}

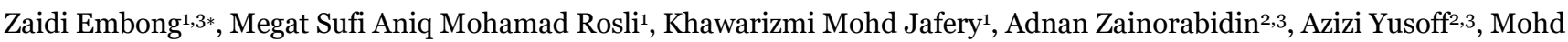
Shahrizal Abdul Aziz ${ }^{4}$ and Nor Zakiah Nor Hashim 5

${ }^{1}$ Department of Physics and Chemistry, Faculty of Applied Science and Technology (FAST), Universiti Tun Hussein Onn Malaysia (UTHM), 84600 Panchor, Muar, Johor, Malaysia

${ }^{2}$ Faculty of Civil Engineering and Built Environment (FKAAB), Universiti Tun Hussein Onn Malaysia (UTHM), 84600

Panchor, Muar, Johor, Malaysia

${ }^{3}$ Research Centre for Soft Soils (RECESS), Integrated Institute of Engineering (IIE), Universiti Tun Hussein Onn Malaysia (UTHM), 84600 Panchor, Muar, Johor, Malaysia

${ }^{4}$ School of Mechanical Engineering, Universiti Sains Malaysia, Engineering Campus, 14300 Nibong Tebal, Penang, Malaysia

${ }^{5}$ Centre of Foundation Studies, Universiti Teknologi MARA, Selangor Branch, Dengkil Campus, 43800 Selangor, Malaysia

In Malaysia, peat make up for around 7.5 \% of the entire land area. The positive effect of the vast wet organic compounds accumulates over a long time has stored high content of soil's carbon which are highly useful as fuel and biomass energy generation. Thus, this study gives an outline of peat pellet as potential biofuel energy. The peat pellets were soaked into several kinds of flammable additives such as petrol, kerosene and diesel. The percentages of $69.41 \%$ of carbon, $28.73 \%$ of oxygen and 0.97\% of silicon were obtained using Energy Dispersive X-ray (EDX). The Fourier-Transformed Infrared (FTIR)- Attenuated Total Reflectance (ATR) Spectroscopy was used to identify the sample. From the spectra, it reveals that most of the additives contribute mainly functional groups with hydroxyl, alcohol and phenol groups were found leading to higher boiling and melting points. The heat combustion properties of peat pellets were evaluated using a calorimeter technique by boiling off $50 \mathrm{ml}$ and $100 \mathrm{ml}$ of water. The pellet with diesel has the highest Q-values and combustion rate due to larger number of carbons in rigid molecular structure. The high amount of unique chemical compound found naturally in diesel known as cetane, ignites effortlessly when heated gives diesel additional advantages in shorter ignition delays as well as longer duration of combustion.

Keywords: biomass; biofuel; calorimetry; peat; SEM-EDX; FTIR-ATR

\section{INTRODUCTION}

As the number of global populations is on the rise and the advancement of industrialisation moving forward, humanity's hunger for energy has reached unparalleled extent. Half or even more energy that we use comes from fossil fuel that was unearthed from deep within the Earth's crust. It is presumed that oil drilling began in the 1850's, and since then we have extracted more than 135 billion tonnes of raw oil to power up our vehicles and provide energy supply to our cities (Kiew F et. al., 2020; Reinjnders L, 2020). These numbers is expected to rise over the years to come. The extensive use of fossil fuel over the past two centuries has deeply affected the nature of our planet (Perry, 2020; Schmidt, 2020). The rising number of greenhouses gases level in Earth's atmosphere and climate changes is heavily linked to burning of oil and gases worldwide. Scientists 
commonly agree that if no intervention comes soon enough, humanity is on a path towards energy resources disaster. Unless we somehow stopped our dependency on fossil fuel to supply energy demands to our daily lives (Hamed \& Peric, 2020). New energy alternative that involves locally available and renewable resources is one of the primary objectives of many governments, scientists and entrepreneurs worldwide. Biomass - the fourth biggest energy source after traditional energy source which is coal, oil, and natural gas, is the major platform and utmost imperative renewable energy selection in present-day times and can be used to produce diverse form of energy (Acharya, Sule \& Dutta, 2012). Due to this, researchers have come up with a decision that, together with the other renewable energy options, biomass is capable providing numerous energy services required in today's society, both locally and abroad. Additionally, as opposed to another renewable, biomass resources are abundant in supplies, common and widespread throughout the globe (Owusu, PA \& Asumuda -Sarkodie S, 2016). Malaysia's geographic location has several merits for extensive use of biomass renewable energy resources (Adon et al., 2012).

As Malaysia inherits the benefits of all year-round moist climate and tropical forests which gives the opportunity for agriculture and tropical rain forest an immediate exploitation (Abril et al., 2011). In biomass, the generation of waste is minimised, meanwhile the waste residue is being turned into useful energy such as heating and electricity, thus support the economy prosperity in Malaysia. Biomass has shown significant implemented status compared to other renewable energies in Malaysia which is approximately $17 \%$ of total implementation and deployment (Syakirah et al., 2019). Such reasons are, biomass is cheaper in the long run compared to natural gas which is expensive (Acharya B et. al, 2012; Owusu, PA \& Asumuda -Sarkodie S, 2016). In today's time, there are plenty of wastes that are biodegradable and plant matter that is functional to be turned into biomass. Annually around the world, 998 million tonnes of agricultural waste which includes crop and animal waste is generated, while in Malaysia, about 1.2 million tonnes per year of agricultural waste is piling up into landfills (Neh, 2020). Using biomass will reduce the negative impacts on the natural environment such as contaminating local habitat and damaging wildlife. On the other hand, using biomass will cause waste residues to decrease in numbers. What this means is that there will be cleaner also new areas opened up for humans to live and reside. Renewability and versatility always show up as advantages of biomass as an energy resource among available alternatives (Sharma, Sarmah \& Dubey, 2020; Lu et al., 2021).

As Malaysia is progressing to become a developing and industrialised country, so does the number of populations that will continue to rise and live. With that being said, so do the energy demands that are needed to power up the energy structure throughout the country. In these times, most of these energy demands are supplied by the use of nonrenewable energy such as coal, petroleum, crude oil, fossil fuels and natural gas. Therefore, the role of indigenous biomass can serve as a potential source for replacing these non-renewable energy (Sameeroddin et al., 2021). Moreover, major recurrence environmental issues in Malaysia involving atmospheric haze are a sombre significance due to biomass burning in Indonesia and frequently triggered by peat fires (Ahmed, Guo \& Zhao, 2016). These fires befall primarily in the dry season ranges from June to September and increase during El Niño years (Putra \& Hiroshi, 2011) which creates devastating effect on local wildlife. Next, copious amount up to billions of Ringgit Malaysia are spend due to damages through the demolition of homes and businesses (Khor, 2019). Furthermore, the fires also release immense volumes of carbon dioxide (greenhouse gas) into the atmosphere (Rena et al., 2020).

Generally, peat has been utilised as the form of energy for a long decade (Dai et al., 2020). Of course, on the flip side, the popularity of peats as one of the energy sources is lesser as opposed to fossil fuel energy due to smaller yield for the output of its energy (Lindroos et al., 2021). Moreover, the extraction process of peat is less economic than imported fossil fuels as example of oil and natural gas is another factor for the application of peat as the primary energy source is not common (Verdolini, Vona \& Popp, 2018). To society, biofuel energy in the form of peat has been overlooked. Not until the late 2oth century where energy crisis started risen, where rapid depletion of fossil fuel due to high dependency of it led to many governments of various countries ventures out to find a new renewable and green energy for their own country (Rahman \& Wahid, 2021). Due to the request for energy is 
mounting, the researchers aimed to assess the role of peat for energy production to meet country immense energy necessities. However, the production and practise of fuel pellets from various biomass are not abundantly explored globally, in which the precise extent is inaccessible due to deficiency of data from numerous countries, predominantly in developing countries (Näzelius et. al., 2013; Pradhan, Mahajani \& Arora, 2018), thus the topic entails further investigation and analysis.

This is why this study was carried out by utilising peat soils as alternatives biofuel pellets in reducing the negative impacts of peat fire burning, and at the same time revising the potentials of energy resources especially biomass to reduce the support the energy demands in the near future. In this study, the experiment is carried out by introducing biofuel pellets which are peat pellets as an alternative energy. This study determines which is the most compatible pellet with additives has more potential to become the new biofuel energy in order to create awareness to the public that fossil fuels are non-renewable, and sooner or later it will become depleted. In addition, the information received from this study can be used by other researchers to conduct their research on biomass. The inclusion of three different additives including petrol, diesel and kerosene in this experiment are to support the enhancement of combustion process for the cylindrical-shaped biofuel pellets. And from here, the best additive will be chosen based on its average Qvalue.

\section{EXPERIMENTAL}

\section{A. Collection of the Peat Soil Samples and Additives}

All of the samples were collected from Kampung Parit Sri Menanti, Parit Botak, Johor, Malaysia (GPS coordinate; N 10 $1^{\circ} 47^{\prime} 42.3^{\prime} \mathrm{N} 103^{\circ} 07^{\prime} 19.9$ "E). For this particular coordinate, the samples were retrieved from 3 different spots, just few metres apart. This is to further enhance the data collection for the peat samples that were taken here in terms of its chemical and physical properties. The peat samples were securely reserved in a specialised bag made from polyethylene to ensure the properties of the sample would be undisturbed. The additives used in this study is petrol, kerosene and diesel, recovered locally from gas stations and shops.

\section{B. Sample Preparation and Calorimetry Analysis}

\section{Peats Pelletisation}

As shown in Figure 1, the drying process was conducted by drying the peat samples into the oven at 110 degrees for 24 hours. After the removal of moisture content from the samples, the peat samples were inserted into the grinding machine for 24 hours and the samples were converted into fine powder state (O'Kelly, 2015). The peat samples in powder form undergoes pelletising process with diameter of $1 \mathrm{~cm}$.

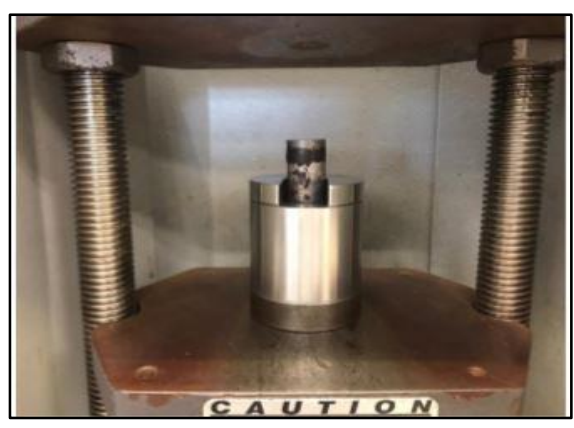

Figure 1. Pelletisation of the peat sample

The peat powder was weighed using analytical balance with weighing limit of the peat powders' which was at $2.5 \mathrm{~g}$. Next, $2.5 \mathrm{~g}$ of wax powder from a candle were inserted into the same mould with the peat powder. The mixture was compressed to 5 tonnes of pressures by the hydraulic compressor for 5 minutes before taken out of the mould.

\section{Biofuel Pellets Preparation}

Few data regarding biofuel pellets must be retrieved first before the pellets rather employed in the calorimeter experiment. The first step was measuring the initial mass of the peat pellets $\left(m_{1}\right)$ by using the analytical mass. Next, the initial volume reading of the peat pellets $\left(V_{1}\right)$ of the peat pellets with the addition of additives such as kerosene were measured. This is done by soaking the peat pellets in $200 \mathrm{~mL}$ of kerosene, then were left for two to three hours inside a beaker.

After the process of drenching the peat pellets in kerosene, immediately the reading of volume of the peat pellets $\left(V_{2}\right)$ left inside the beaker was taken. The amount of additives that was absorbed into the pellet were calculated using the following Equation (1): 


$$
V_{3}=V_{1}-V_{2}
$$

(1) Where,

Where,

$V_{3}=$ the volume of additive inside the pellet,

$V_{1}=$ the volume before the pellet soak in an additive,

$V_{2}=$ the volume after the pellet soak in an additive

The soaked pellets were removed from the beaker, cleaned and dried with tissue carefully. Next, the mass of the peat pellet $\left(\mathrm{m}_{2}\right)$ after it was soaked with additives were determined by the analytical mass. The difference in mass of the peat pellet before and after it was drenched in additives calculated by using the following Equation (2):

$$
m_{a}=m_{1}-m_{2}
$$

Where,

$m_{a}=$ the mass of additive absorbed into the pellet,

$m_{1}=$ the mass before the pellet soak in an additive,

$m_{2}=$ the mass after the pellet soak in an additive.

The pellet with the addition of additives were dried by leaving the sample under the rays of sunlight for 6 hours to ensure equilibrium absorption of the additives were fully achieved. Afterwards, the mass of the peat sample $\left(m_{4}\right)$ with the new mass value of the vaporised additives $\left(m_{5}\right)$, were retrieved using Equation (3) below:

$$
m_{b}=m_{3}-m_{4}
$$

Where,

$m_{\mathrm{b}}=$ the mass of additive inside pellet that evaporates to the air,

$m_{3}=$ the mass of additive inside pellet before the drying process to sunlight,

$m_{4}=$ the mass of additive inside pellet after the drying process to sunlight.

Mass of vaporised additive from the initial value after it was dried under the sunlight was calculated as in the equation below:

$$
m_{\mathrm{c}}=m_{\mathrm{a}}-m_{\mathrm{b}}
$$

$m_{\mathrm{c}}=$ the mass value of vaporised additive from initial value of additive absorbed,

$m_{\mathrm{a}}=$ the mass value of additive absorbed into the peat pellet, $m_{\mathrm{b}}=$ the mass value of additive inside pellet that evaporates to the air.

\section{Heat Capacity Analysis using Calorimetry Technique}

Before the experiment starts, the mass of the water inside of the beaker have been recorded to be inserted in Equation (5) until (8). By referring to Figure 2, two beakers were filled up with water until it reaches the volume of $50 \mathrm{~mL}$ and $100 \mathrm{~mL}$, as the combustion trial were conducted into two phases. The beakers were placed on tripod stand while peat pellet with additives were placed below the tripod stand. The initial temperature of the water was measured by using a thermometer, then the peat pellet sample ignited with the water's temperature began to rise. The recorded time was taken when the combustion of the peat pellet has exhausted. After the peat pellet's combustion extinguished, another reading of temperature of the water was documented indicates final temperature of the water. The difference of water temperature before and after combustion of peat pellet sample was recorded.

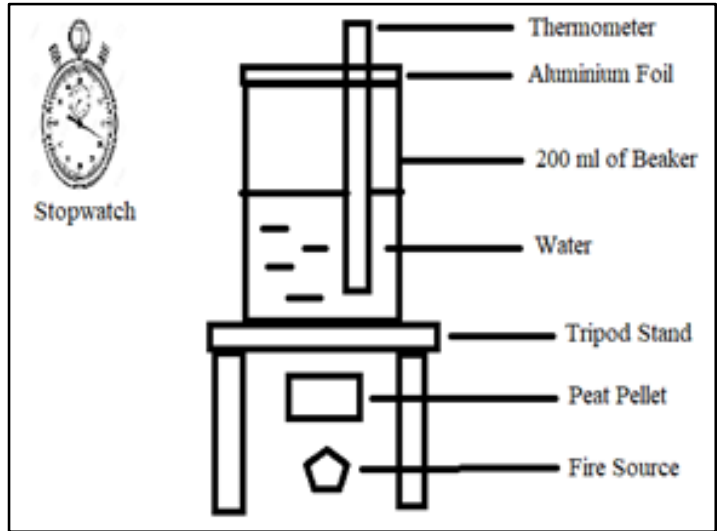

Figure 2. The schematic diagram for the calorimetry measurement

$Q_{0}=m c \Delta T$

$\Delta Q=\left(\frac{\Delta \mathrm{m}}{\mathrm{m}}+\frac{\Delta \mathrm{c}}{\mathrm{c}}+\frac{\delta \mathrm{T}}{\Delta T}\right) \times Q_{0}$

$Q=Q_{0}+\Delta Q$

$\frac{Q}{t}=\frac{Q_{0}+\Delta Q}{t+\Delta T}$ 
Where,

$Q_{0}=$ the heat of combustion,

$m=$ the mass of the water,

$c=$ the specific heat capacity of the water,

$\Delta T=$ the temperature different, $\Delta Q=$ the uncertainty for heat capacity of combustion,

$\Delta m=$ the uncertainty for mass of water,

$\Delta c=$ the uncertainty for specific heat of water,

$\delta T=$ is the uncertainty for the temperature

$t=$ is the time taken

$\frac{Q}{t}=$ is the rate of combustion

\section{Sample Characterisation using SEM-EDX and FTIR-ATR}

\section{Surface and Elemental Analysis using SEM-EDX}

The Scanning Electron Microscopy (or the SEM) analysis was used to investigate the surface morphology of the peat soil of control pellet. The SEM analysis provides the chemical analysis in area as one micrometre in diameter. The elemental analysis could be done on any feature observed with an integrated Energy Dispersive X-ray (EDX) spectroscopy. In this study, only the raw peat soil which contained no additives was analysed using the SEM-EDX.

\section{Functional Group Analysis using FTIR-ATR}

The IR spectra of the control peat biofuel peat powder and containing biofuel additives were recorded using FTIR spectroscopy (Agilent Cary 630 FTIR Spectrometer) attached with an accessory ATR. The measured IR spectrum setting ranges from $4000 \mathrm{~cm}^{-1}$ to $2000 \mathrm{~cm}^{-1}$.

\section{RESULTS AND DISCUSSION}

\section{A. Sample Composition and Morphology Analysis using SEM-EDX}

The SEM analysis was used to investigate the surface of the raw peat soil. The surface of the raw peat soil retrieved demonstrates uneven crater-like surface as shown in Figure 3. The EDX spectrum for the raw peat soil as in Figure 4 clearly illustrates the presence of carbon, oxygen and silicon, with carbon as the main element in the sample. The EDX analysis of the raw peat soil reveals that carbon element constitutes of $69.41 \%$ of average atomic mass which is more than half from the total weight. The presence of oxygen is the second heavy-presence composite in the raw peat soil with $28.37 \%$ of the average atomic mass.

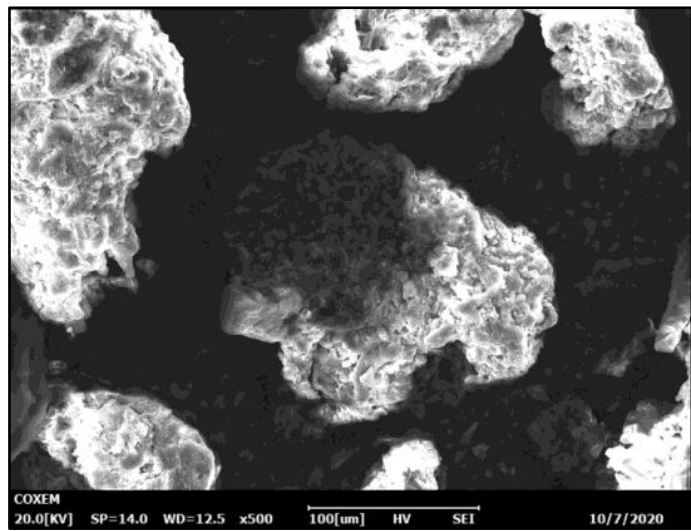

Figure 3. The morphology structure of raw peat from SEM analysis

With both carbon and oxygen existence in the raw peat soil, it would make the biofuel pellet to be easily ignited thus the combustion trial is deemed possible. Outside of both carbon and oxygen, there are other traces of elements that is present inside of the raw peat soil, which is silicon with $0.97 \%$ of average atomic mass.

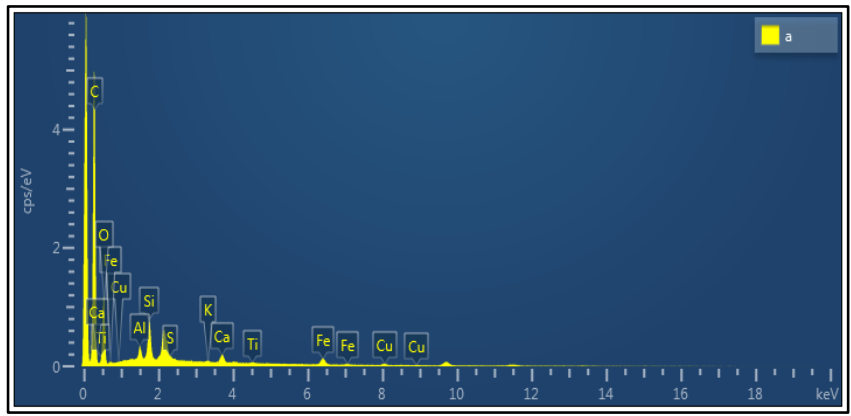

Figure 4. The EDX Spectrum for raw peat soil

\section{B. Functional Group Analysis using FTIR-ATR}

FTIR Spectroscopy was used to identify the functional groups existed within the raw peat sample without inclusion of additives and with the addition of petrol, kerosene and diesel, correspondingly as shown in Figure 5. The first strong and broad intensity peak with wavelength ranges between the value of $3570 \sim 3200 \mathrm{~cm}^{-1}$ are due to $\mathrm{H}$-bonded and $\mathrm{O}-\mathrm{H}$ stretch in the form of hydroxyl compound, alcohol and phenol. The FTIR spectra of the peat samples powder shows 
the first peak of all samples are at $3345.10 \mathrm{~cm}^{-1}$, $3343.10 \mathrm{~cm}^{-1}$, 3345.09 $\mathrm{cm}^{-1}$ and $3346.26 \mathrm{~cm}^{-1}$ for the control, kerosene, petrol and diesel peat powders, respectively.

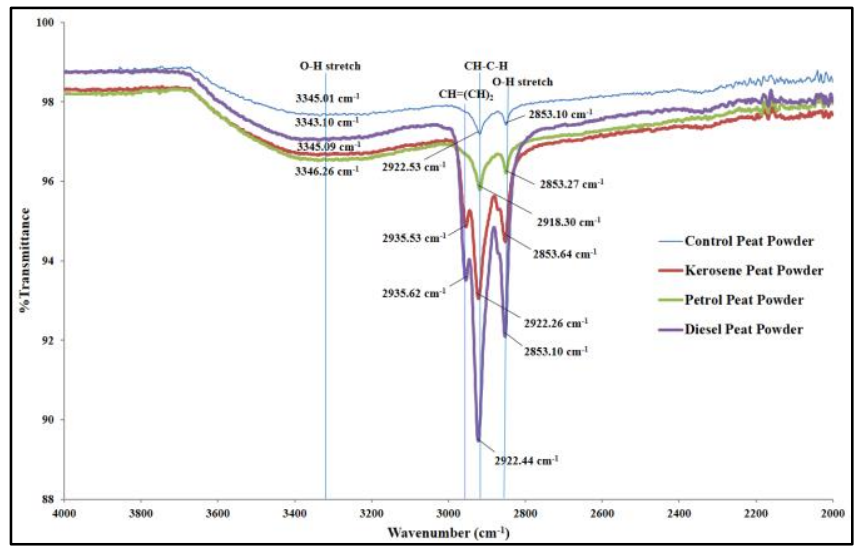

Figure 5. Overlay FTIR Spectra without Addition of Additives and Inclusion of Kerosene, Petrol and Diesel Additives

Next, the carboxylic acids group exists in the absorption range between $3500 \sim 2400 \mathrm{~cm}^{-1}$ caused by infrared vibration of $\mathrm{O}-\mathrm{H}$ stretch. Carboxylic acids are likely to have higher boiling points than water due to the increased surface area and inclines to form stabilised dimer. Carboxylic acids group are easier to be evaporated or boiled as dimers by breaking dimers bond or vaporised the entire arrangements. Next, the absorption range between $3100 \sim 3000 \mathrm{~cm}^{-1}$ is the range of $-\mathrm{CH}=\mathrm{C}-\mathrm{H}$ asymmetric stretch for alkenes group. The asymmetric group of $-\mathrm{CH}(\mathrm{CH})_{2}$ vibrations are found between $2935 \sim 2915 \mathrm{~cm}^{-1}$ in the form of saturated aliphatic compound-lipids. Saturated aliphatic compound-lipids are extremely flammable and allow the usage of hydrocarbons as fuel. The wavenumber allocated for control peat powder sample is at $2922.53 \mathrm{~cm}^{-1}, 2918.30 \mathrm{~cm}^{-1}$ for petrol peat powder sample, $2922.26 \mathrm{~cm}^{-1}$ for kerosene peat powder sample and diesel peat powder sample at $2922.44 \mathrm{~cm}^{-1}$.

\section{Samples Q-values Analysis using Calorimetry Method}

\section{Heat of Combustion, $Q$-Value for $50 \mathrm{ml}$ of water Heating from Peat Pellets with Additives}

The heat capacity of combustion, or known as $\mathrm{Q}$ value experiment, was performed by using the calorimetry technique. The heat capacity of combustion was calculated by using the Equation (5) until (8). The trial and experimentation for Q-value by using the $50 \mathrm{ml}$ water in calorimeter was repeated for 5 times to obtain the average value of $\mathrm{Q}$-value. Figure 6 depicts the average $\mathrm{Q}$-value for each pellet that was burned under the $50 \mathrm{ml}$ water heating process.

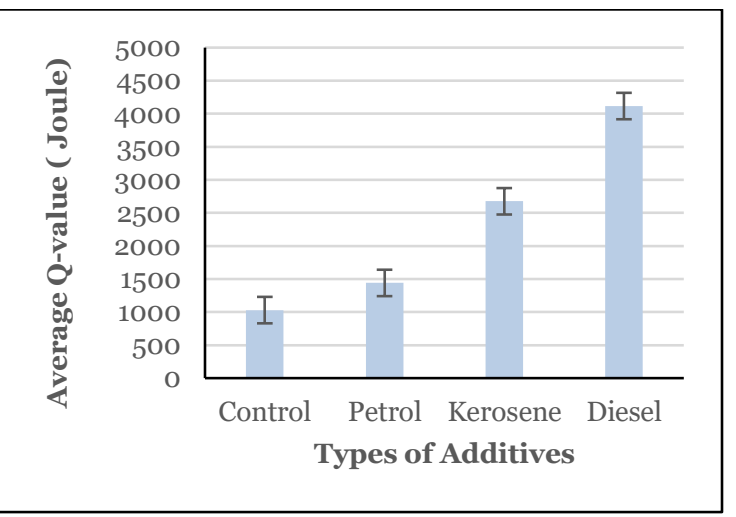

Figure 6. The average Q-value for all type of additive for boiling off $50 \mathrm{ml}$ of water

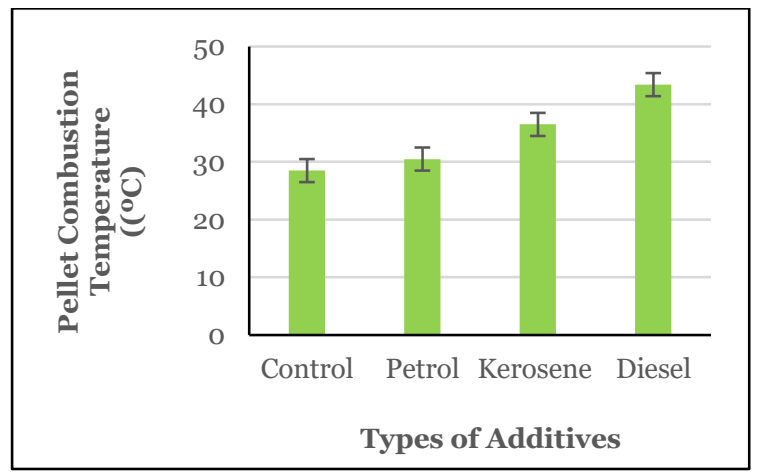

Figure 7. The pellet combustion temperature for all type of additive for boiling off $50 \mathrm{ml}$ of water 


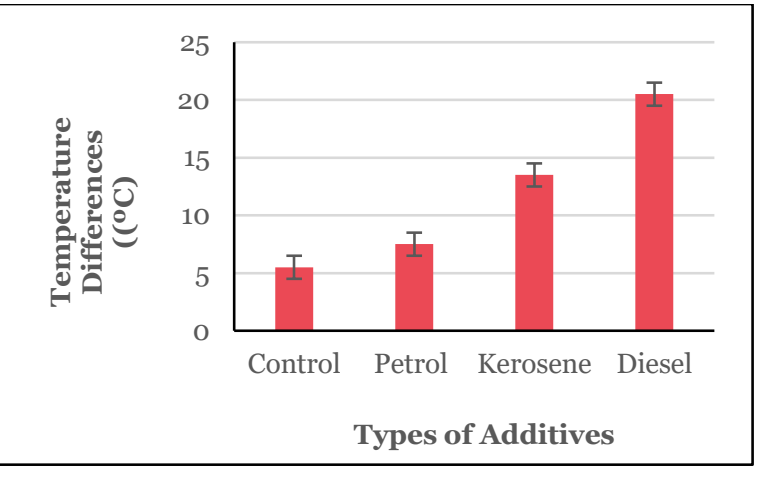

Figure 8. The temperature difference for all type of additives for boiling off $50 \mathrm{ml}$ of water

Based on the Figure 6, the control pellet possessed the lowest Q-value compared to other pellets that contained flammable additives. This result is expected due to the reason of the absence of combustible compound to encourage the combustion of the pellet itself. The average Q-value of control pellet is $Q=(1029+31)$ Joule. The lower Q-value is due to the lack of flammable compound that encourages combustion. Furthermore, since there was no flammable element in the pellet, the final temperature of the $50 \mathrm{ml}$ of water is inadequate compared to its counterpart which is around $28{ }^{\circ} \mathrm{C}-29{ }^{\circ} \mathrm{C}$ from the initial temperature of $23{ }^{\circ} \mathrm{C}$ (Figure 7). This gave only a mere $5{ }^{\circ} \mathrm{C}-6{ }^{\circ} \mathrm{C}$ of temperature different (Figure 8). The low temperature of $50 \mathrm{ml}$ water at the end of the control pellet's combustion concluded that the heat capacity of combustion from the control pellet is insignificant and only enough to warm the water up.

Petrol possessed the second lowest Q-value amongst the four-peat pellet's type. The average Q-value of petrol pellet is $\mathrm{Q}=(1440+40)$ Joule. Even though the petrol pellet's Q-value is lower than kerosene and diesel pellet, it is higher than control pellet. The reason behind it is because the characteristic of flammable element that is present inside the pellet itself which is petrol. Petrol is known for its high tendency to be easily evaporate into the surrounding air, thus, leaving only a small fraction of its left during the combustion process. As a result, the heat from the petrol pellet's combustion is not high enough to heat the $50 \mathrm{ml}$ of water and only warms it up. This gave final temperature of the $50 \mathrm{ml}$ water which is recorded between $30^{\circ} \mathrm{C}-31^{\circ} \mathrm{C}$ (Figure 7) and value of temperature different of $7^{\circ} \mathrm{C}-8^{\circ} \mathrm{C}$ (Figure 8).

The pellet with kerosene has the second highest of Q-value in this $50 \mathrm{ml}$ of water heating process, with its value is $\mathrm{Q}=$
$(2675+45)$ Joule. Kerosene pellet showed considerably higher Q-value than the control and petrol pellet, but it is still lower than the diesel pellet. Kerosene is a highly combustible chemical liquid. Just like the diesel, the hydrocarbons make up most of the component of the kerosene but kerosene burns at a different rate and ignites at a different rate. But the kerosene pellet's combustion is a bit high enough to heat the $50 \mathrm{ml}$ of water up to $36^{\circ} \mathrm{C}-37^{\circ} \mathrm{C}$ from the initial $23^{\circ} \mathrm{C}$ (Figure 7). This gave the temperature different between $13^{\circ} \mathrm{C}-14^{\circ} \mathrm{C}$, a bit smaller than diesel (Figure 8).

The highest average Q-value comes from the diesel pellet, which is recorded at significant value compared to the other three types of pellet. The average Q-value of the diesel is $\mathrm{Q}=$ $(4116+53)$ Joule. This means that the heat that is released from the diesel pellet is the highest in this $50 \mathrm{ml}$ water combustion process. The final temperature of the $50 \mathrm{ml}$ water after the diesel pellet's combustion is $43^{\circ} \mathrm{C}-44^{\circ} \mathrm{C}$ (Figure 7). This resulted in giving the temperature different of $20^{\circ} \mathrm{C}-$ $21^{\circ} \mathrm{C}$ (Figure 8). The characteristic of diesel is that it is made of mostly of hydrocarbon, whereas if introduced towards high enough heat, the vapour that permeated from the pellet becomes flammable when mixed with the surrounding air. Diesel contains a cetane number, which reflects to its quality as a diesel fuel. The higher the cetane number, the effortless it is to ignite the diesel (Wang, Yin \& Ni, 2021).

\section{Heat of Combustion Q-value for $100 \mathrm{ml}$ Water Heating from Peat Pellets with Additives}

The same calorimetry technique was used in order to acquire the heat capacity of combustion (Q-value) of the peat pellets, only this time $100 \mathrm{ml}$ of water was used. Figure 9 below depicts the average Q-value for each pellet that was burned under the $100 \mathrm{ml}$ water heating process.

Referring to the bar chart in Figure 9, it revealed that the control pellet encompassed the lowest Q-value which is $\mathrm{Q}=$ $(4939+62)$ Joule. The final temperature for the $100 \mathrm{ml}$ after the combustion process is between $35^{\circ} \mathrm{C}-36^{\circ} \mathrm{C}$, from the initial temperature of $23^{\circ} \mathrm{C}$. This gave out the temperature different ranges between $12^{\circ} \mathrm{C}-13^{\circ} \mathrm{C}$. As expected, the heat capacity of combustion of control pellet is the lowest compared to other three type of pellets that contained flammable additives. This is because there is no combustible 
element inside the control pellet to assists the combustion process.

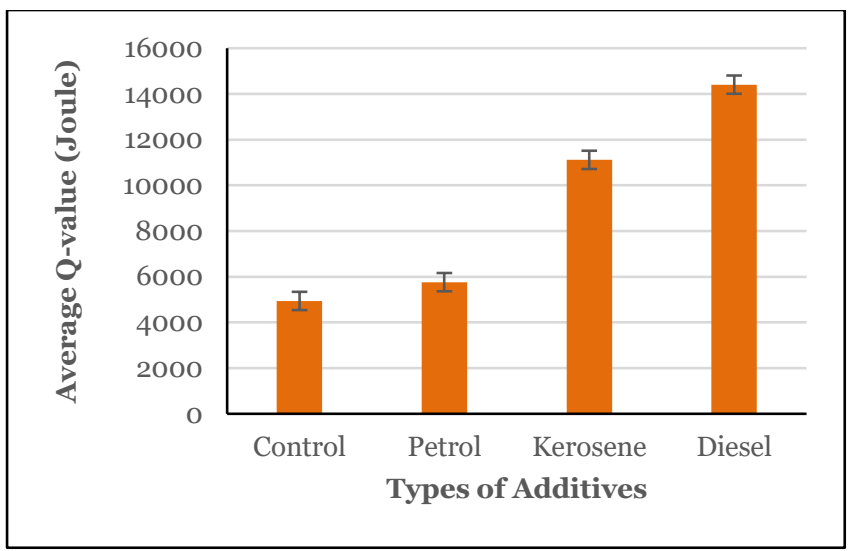

Figure 9. The average Q-value for all type of additive for boiling off $100 \mathrm{ml}$ of water

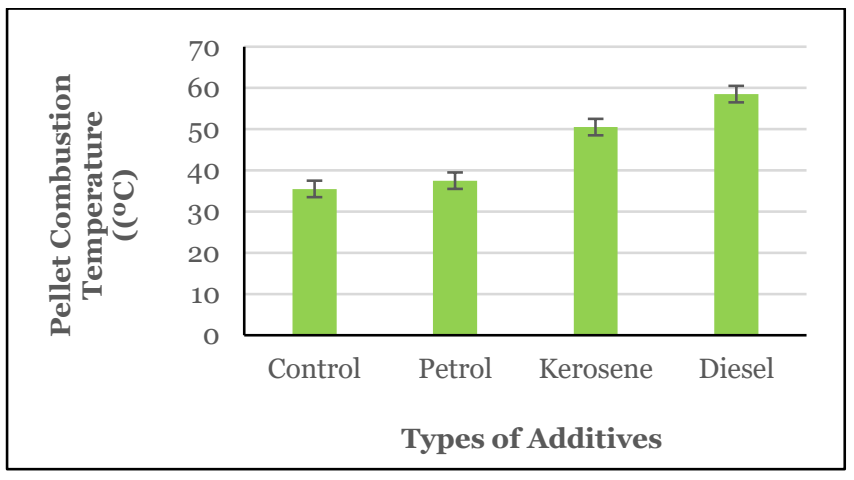

Figure 10. The pellet combustion temperature for all type of additive for boiling off $100 \mathrm{ml}$ of water

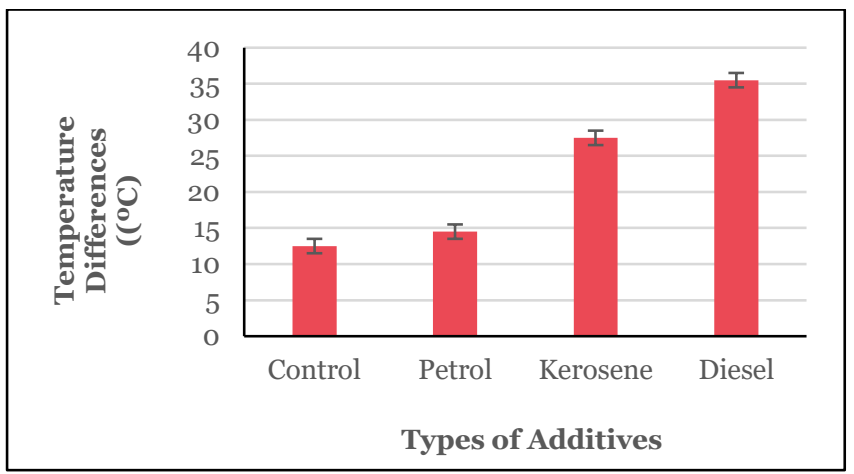

Figure 11. The temperature difference for all type of additive for boiling off $100 \mathrm{ml}$ of water

The second-highest Q-value for this experimentation was kerosene, with its value was $\mathrm{Q}=(11113+90)$ Joule. The Qvalue shown here in the bar chart in Figure 9 showed that there is a major increase in value right after the petrol pellet's Q-value. The final temperature of the $100 \mathrm{ml}$ water after the combustion process is between $50^{\circ} \mathrm{C}-51^{\circ} \mathrm{C}$ (Figure 10), therefore gave the temperature different ranges from $27^{\circ} \mathrm{C}-$ $28^{\circ} \mathrm{C}$ (Figure 11). The presence of huge amounts of hydrocarbons gave the ability for the kerosene pellet to produced higher intensity of heat combustion towards the water inside the beaker.

The highest Q-value for this combustion testing was none other, the diesel pellets itself, in which the value was (14406 + 106) Joule. The final temperature of the $100 \mathrm{ml}$ water as soon as the combustion process completed was between $58^{\circ} \mathrm{C}$ $-59^{\circ} \mathrm{C}$ (Figure 10), hence gave the result of temperature different ranges between $35^{\circ} \mathrm{C}-36^{\circ} \mathrm{C}$ (Figure 11). Identical to the kerosene's characteristic, diesel is hugely made up of significant number of hydrocarbons and cetane numbers, which contributed to the diesel pellet's highest heat capacity of combustion among these 4 types of pellets.

\section{Heat of Combustion Q-value Comparison of 5oml and $100 \mathrm{ml}$ Water Heating from Peat Pellets with Additives}

As stated by the first law of thermodynamics, energies are incapable to be made nor to be destroyed, however the energy can be transmitted or altered from one form into another (Speight, 2020). Based from the heat capacity of combustion of the pellet's measurement, a calorimeter set-up was used as the medium for the heat energy to be transferred from the pellet's combustion to the water. The exothermic reaction was measured from the combustion energy discharged from the pellets. The heat energy was then transmitted to the calorimeter set-up or the water inside the beaker, in this case. The heat energy then raised the temperature of water inside the beaker until it reached the maximum potential value based upon the amount of heat that was conveyed (Jin et al., 2021). The heat capacity of combustion experimentation was performed by using $50 \mathrm{ml}$ and $100 \mathrm{ml}$ of water. The reason behind this was to determine whether the amount of volume of water would affect the absorbed heat from the combustion of the pellets. By referring to Figure 12, it depicted the comparison of the average Q-value of both $50 \mathrm{ml}$ and $100 \mathrm{ml}$ boiling of water. According to Equation (5), the heat capacity of combustion is directly proportional to the mass of the water, hence, the mass of $50 \mathrm{ml}$ is $0.049 \mathrm{~kg}$ and for the 100 ml's mass of water is twice that number which is $0.098 \mathrm{~kg}$. As 
a result, the average Q-value for the $100 \mathrm{ml}$ of water is higher because of the mass of water greater (Bai et al., 2021).

Based on the data received from these combustion experimentations, it is to be concluded that the volume of the water affected the recorded temperature different after the combustion testing. The noticeable large temperature different produced by kerosene and diesel pellets resulted in increased the Q-value almost twice the amount compared to the control and petrol pellets. The explanation behind this is the presence of large numbers of hydrocarbons in these two additives. The structure of the kerosene often ranges from 12 carbon atoms to 15 carbon atoms while diesel contained rigid molecule structure whereas the carbon chains range from 16 atoms. The higher the number of carbons in the hydrocarbon, the larger the enthalpy change of the pellets' combustion (Kumar, Jones \& Hanna, 2009). Given that the diesel pellets contained larger carbon number, is possessed the highest average Q-values for both $50 \mathrm{ml}$ and $100 \mathrm{ml}$ water heating process. The cetane (hydrocarbon with chemical formulas $\mathrm{C}_{16} \mathrm{H}_{34}$ and $\left.\mathrm{CH}_{3}\left(\mathrm{CH}_{2}\right)_{14} \mathrm{CH}_{3}\right)$ that are presence in this fuel, is known to have higher number in diesel allows shorter ignition delays and longer duration of combustion.

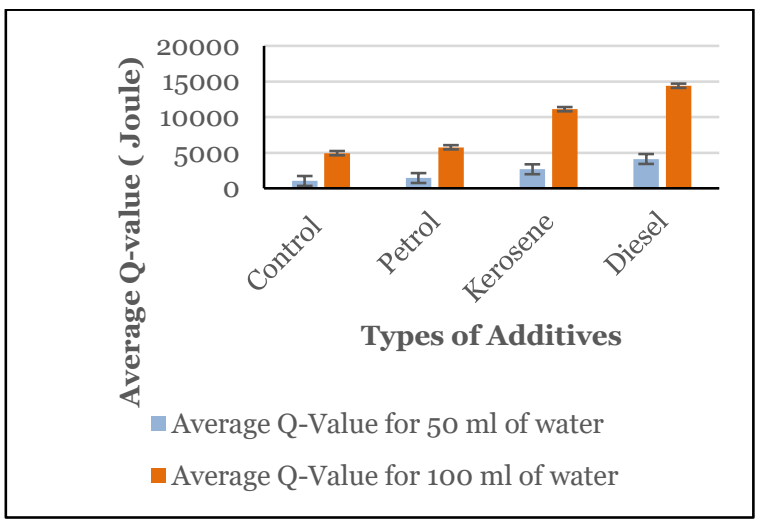

Figure 12. Comparison for boiling of $50 \mathrm{ml}$ and $100 \mathrm{ml}$ of water

\section{Heat of Combustion Per Time, Q/t for $50 \mathrm{ml}$ Water Heating from Peat Pellets with Additives}

The Q-values per time of the pellets was determined by the time taken for the pellets' combustion to be completely exhausted. Figure 13 below portrayed the trend of the average Q-values per time of the pellets for $50 \mathrm{ml}$ water.

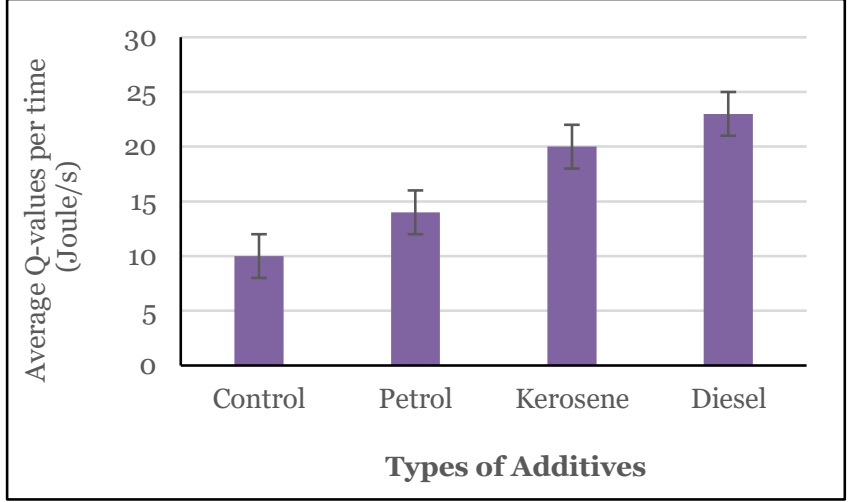

Figure 13. The rate of Q-Value for all type of additives for boiling off $50 \mathrm{ml}$ of water

Based from Figure 13, the control pellets produced the lowest Q-values per time, which is $\mathrm{Q} / \mathrm{t}=(10+0.21) \mathrm{Joule} / \mathrm{s}$. The duration of the time taken for the control pellets to be completely depleted in terms of combustion was in ranges between $1.63-2.15$ minutes. This short time of combustion is due to the fact that the control pellets lack of flammable compound that encourages the incineration process. The general elements contain in the raw peat soil are carbon, oxygen and silicon (Hou et al., 2020). The carbon and oxygen are directly involved in combustion process and released the energies; however, it is only for certain degrees before these two elements were completely exhausted (Kamran G et al., 2018).

\section{Heat of Combustion Per Time, $Q / t$ for $100 \mathrm{ml}$ Water Heating from Peat Pellets with Additives}

The calculation of the heat capacity of combustion per time was repeated by using the data that was received from $100 \mathrm{ml}$ water burning of pellets. Based on Figure 14 shown below, there is a new trend to the bar charts of average Q-values per time for $100 \mathrm{ml}$ of water. It is presented that the highest Qvalues per time for $100 \mathrm{ml}$ water heating of pellets is the control pellet, with value of $Q / t=(63+0.53) \mathrm{Joule} / \mathrm{s}$, and the time taken for the pellet to completely burnt out is between $1.30-1.49$ minutes. The justification of why the heat capacity of combustion per time for control pellet is the highest due to the short time taken before the pellet is exhausted from being burnt out. This data is further strengthened from the Equation (8), which stated that the Q-values is inversely proportional to the time taken. 


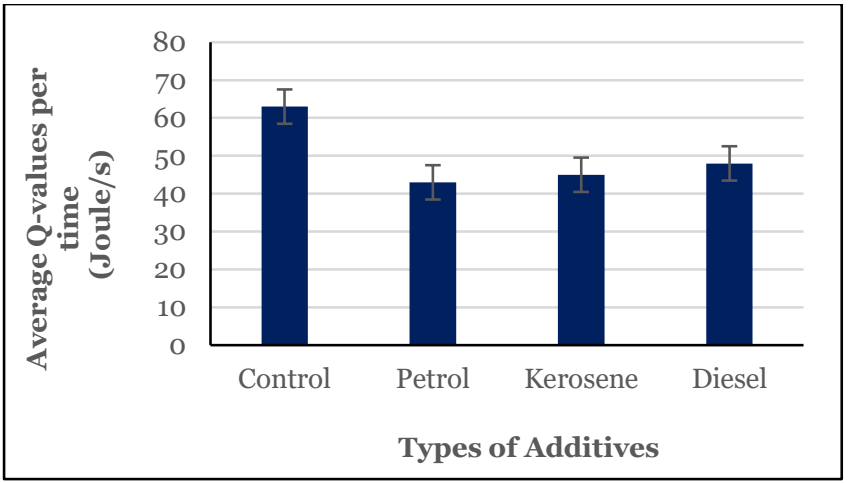

Figure 14. The rate of Q-Value for all type of additives for boiling off $100 \mathrm{ml}$ of water

The lowest rate of heat capacity of combustion belonged to petrol pellet. The average Q-values per time for petrol pellet is $\mathrm{Q} / \mathrm{t}=(43+0.19) \mathrm{Joule} / \mathrm{s}$ and the time taken for the pellet to be completely burnt out is between $2.20-2.45$ minutes. The second lowest rate of heat capacity of combustion is the kerosene pellet, with its average $\mathrm{Q}$-values of $\mathrm{Q} / \mathrm{t}=(45+0.23)$ Joule/s and duration of the combustion is in ranged between 4.41 - 5.20 minutes. Lastly, the second highest of rate of heat capacity of combustion is the diesel pellet in which its average $\mathrm{Q}$-values is $\mathrm{Q} / \mathrm{t}=(48+0.31)$ Joule/s, and the time taken for the diesel pellet to be completely extinguished is between 5.59 -6.20 minutes.

6. Comparison of Heat of Combustion Per Time, $Q / t$ for 50 $\mathrm{ml}$ and $100 \mathrm{ml}$ Water Heating from Peat Pellets with Additives

The data that was obtained from these two experimentations which is the heat capacity of combustion per time for both 50 $\mathrm{ml}$ and $100 \mathrm{ml}$ are made into a series of bar charts for comparison purpose as shown in Figure 15 below:

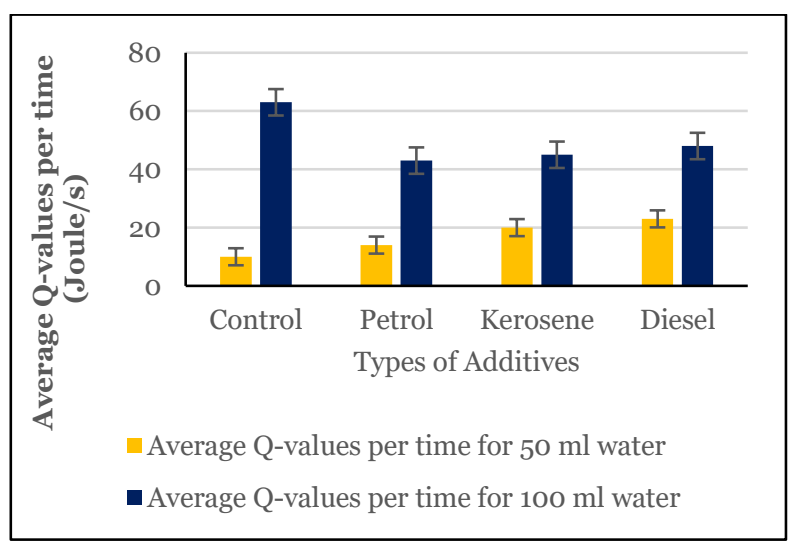

Figure 15. Comparison of rate of Q-value for all type of additives for boiling off $50 \mathrm{ml}$ and $100 \mathrm{ml}$ of water.
The average Q-values per time for $100 \mathrm{ml}$ water heating with petrol, kerosene and diesel showed a significant increase in Q-values compared to the $50 \mathrm{ml}$ water heating, about $50 \%$ increment. In accordance with Equation (8), which stated that the rate of heat capacity of combustion is influenced by the mass of the water and the time taken for the peat pellets to be completely extinguished. The time taken for the peat pellets to be completely burnt for each of the flammable additives is almost identical, in which the ranges of time different does not exceed more than 7 minutes. From the Figure 14 above, the mass for $100 \mathrm{ml}$ water (0.098 kg) gave larger Q-values per time compared to the mass for $50 \mathrm{ml}$ water $(0.049 \mathrm{~kg})$.

The notable different of data that was interpreted in this direct comparison is the control pellet which it has the highest rate of heat capacity of combustion compared to the pellets that contained flammable additives in them. Previously in Figure 9, it showed that the control pellet has the lowest average Q-values compared to the rest of the pellet with additives. However, due to the short time taken for the combustion, this gave out a large amount of rate of heat. As stated from the Equation (8), the rate of heat is inversely proportional to the time taken for the peat pellets to be completely burnt out. Therefore, the average Q-values per time of control pellets has the highest rate of heat compared to other respective pellets with additives in $100 \mathrm{ml}$ water heating, but for the $50 \mathrm{ml}$ of water heating, the diesel pellet possessed a higher rate of heat capacity of combustion.

Next, according to the Figure 13, the petrol pellets produced the second lowest $\mathrm{Q}$-values per time, which is $\mathrm{Q} / \mathrm{t}=(14+$ o.20) Joule/s, a little bit of an increment compared to the control pellets. The time taken for the petrol pellets to be completely burnt up ranges between $2.30-2.52$ minutes. Again, this data showed a little bit of a gain compared to the control pellets. The petrol additive inside of the pellets gave the pellets a little bit of a boost in terms of combustion energy for the pellets to remain burning for about 30 seconds more. Compared to other two type of additives which are kerosene and diesel, the petrol additive gave the lowest heat capacity of combustion per time or $\mathrm{Q} / \mathrm{t}$.

The kerosene pellet possessed the second highest average $\mathrm{Q}$-values per time, in which the values are $\mathrm{Q} / \mathrm{t}=(2 \mathrm{O}+0.24)$ Joule/s. The time taken before the kerosene pellets to be 
completely drained out in terms of combustion is between $4.50-5.30$ minutes. These data showed that it is almost doubled the amount of time before the burning completely exhausted for the kerosene pellets compared to the petrol pellet. The kerosene has greater carbon atoms compared to the petrol pellet, thus gave it a much longer duration of combustion, also kerosene has low tendency to be easily evaporated into the air unlike petrol (Cheremisinoff \& Rosenfeld, 2009).

The highest average Q-values per time in $50 \mathrm{ml}$ water for burning pellets are the diesel pellet, in which the value is $\mathrm{Q} / \mathrm{t}$ $=(23+0.26) \mathrm{Joule} / \mathrm{s}$. The diesel pellet also has the longest duration of combustion before being completely burnt out which is between $5.50-6.30$ minutes. Diesel shown to have the best performance of heat capacity of combustion per time in this $50 \mathrm{ml}$ water for burning pellet investigation. The reason behind this is that diesel has the lowest tendency to be evaporated because it has larger molecular structure and much heavier compound (Hoang, Ölçer \& Nižetić, 2021). Hence, the time of combustion is much longer prolonged before the diesel pellets becomes fully exhausted.

\section{CONCLUSIONS}

Several conclusions from this work are summaries as follows: 1. Peat soil was chosen as the potential candidate to be the alternative to become the low-cost energy production in Malaysia.

2. The raw peat soil was taken from the sampling location, then it was dried and undergone pelletising process. After that, the pellet-form peat soil was soaked into flammable additives such are petrol, kerosene and diesel.

3. The Scanning Electron Microscopy (SEM) was used to examine the surface morphology of the raw peat soil. It was shown that the surface of the peat was uneven and irregular. The Energy Dispersive X-ray (EDX) was utilised to recognise the percentages of carbon and other elements that is present inside of the raw peat soil. The spectra had shown the presence of carbon (69.41\%), oxygen (28.37\%) and silicon (0.97\%).

4. The Fourier-Transform Infrared (FTIR)-ATR Spectroscopy was used to identify the functional group that existed inside of the peat powders with or without the additives. From the data of spectra that was obtained from this analysis, it was shown that there was a presence of hydroxyl compound, alcohol and phenol, in which leads to higher boiling point and melting point. The carboxylic acids have the tendency to have a higher boiling point than water because of the increased surface of the area and to form stabilised dimers. The FTIR spectrum also detected the saturated aliphatic compound-lipids, which its characteristic is very flammable, and it allows the use of hydrocarbon as fuel.

5. The heat of combustion for $50 \mathrm{ml}$ and $100 \mathrm{ml}$ water heating from peat pellets with additives respectively were conducted. It is concluded that the pellet with diesel has the highest Q-values compared to the rest of the pellets type. The reason was that diesel has larger number of carbons in rigid molecular structure (higher cetane number), thus it have shorter ignition delays as well as longer duration of combustion.

\section{ACKNOWLEDGMENT}

The authors would like to thank the financial support by GPPS (Vot: H624) provided by Research Management Centre (RMC), Universiti Tun Hussein Onn Malaysia (UTHM).

\section{REFERENCES}

Abril, N, Gion, JM, Kerner, R, Müller-Starck, G, Cerrillo, RMN, Plomion, C, Renaut, J, Valledor, L \& Jorrin-Novo, JV 2011, 'Proteomics research on forest trees, the most recalcitrant and orphan plant species', Phytochemistry, vol. 72, no. 10 pp. 1219-1242. doi: 10.1016/j.phytochem.2011.01.005.

Acharya, B, Sule, I \& Dutta, A 2012, 'A review on advances of torrefaction technologies for biomass processing', Biomass Conversion and Biorefinery, vol. 2, no. 4, pp. 349-369. doi: 10.1007/s13399-012-0058-y.

Ahmed, M, Guo, X \& Zhao, XM 2016, 'Determination and analysis of trace metals and surfactant in air particulate matter during biomass burning haze episode in Malaysia', Atmospheric Environment, vol. 141, pp. 219-229. doi: 
10.1016/j.atmosenv.2016.06.066.

Bai, M, Wang, F, Liu, J \& Wang, Z 2021, 'Experimental and numerical studies of heat and mass transfer performance and design optimization of Fan-coil with high supply chilled water temperature in air-conditioning system', Sustainable Energy Technologies and Assessments, vol. 45, p. 101209. doi: 10.1016/j.seta.2021.101209.

Cheremisinoff, NP \& Rosenfeld, P 2009, 'The petroleum industry', in Handbook of Pollution Prevention and Cleaner Production - Best Practices in The Petroleum Industry. Elsevier, pp. 1-97. doi: 10.1016/B978-0-8155-20351.10001-6.

Dai, S, Bechtel, A, Eble, CF, Flores, RM, French, D, Graham, IT, Hood, MM, Hower, JC, Korasidis, VA, Moore, TA \& Püttmann, W 2020, 'Recognition of peat depositional environments in coal: A review', International Journal of Coal Geology, vol. 219, pp. 103383. doi: 10.1016/j.coal.2019.103383.

Hamed, TA \& Peric, K 2020, 'The role of renewable energy resources in alleviating energy poverty in Palestine', Renewable Energy Focus, Elsevier Ltd, pp. 97-107. doi: 10.1016/j.ref.2020.09.006.

Hoang, AT, Ölçer, AI \& Nižetić, S 2021, 'Prospective review on the application of biofuel 2,5-dimethylfuran to diesel engine', Journal of the Energy Institute, Elsevier BV, pp. 360-386. doi: 10.1016/j.joei.2020.10.004.

Hou, R, Zhang, Y, Feng, H, Chen, Y \& Chen, H 2020, 'Effects of sulfonated peat on $\mathrm{Cr}$ chemical fraction in soil and $\mathrm{Cr}$ uptake in Pak-choi', Journal of Environmental Chemical Engineering, vol. 8, no. 5, pp. 104278. doi: 10.1016/j.jece.2020.104278.

Jin, X, Wu, F, Xu, T, Huang, G, Wu, H, Zhou, X, Wang, D, Liu, $\mathrm{Y} \&$ Lai, AC 2021, 'Experimental investigation of the novel melting point modified Phase-Change material for heat pump latent heat thermal energy storage application', Energy, vol. 216, pp. 119191. doi: 10.1016/j.energy.2020.119191.

Kheng Khor, S 2019, RM1 lawsuit against Indonesia for the annual haze, viewed 21 April 2021, <https://www.malaysiakini.com/news/492206>.

Kumar, A, Jones, D \& Hanna, M 2009, 'Thermochemical biomass gasification: a review of the current status of the technology', Energies, vol. 2, no. 3, pp. 556-581. doi: 10.3390/en20300556.

Lindroos, TJ, Mäki, E, Koponen, K, Hannula, I, Kiviluoma, J \& Raitila, J 2021, 'Replacing fossil fuels with bioenergy in district heating - Comparison of technology options',
Energy, pp. 120799. doi: 10.1016/j.energy.2021.120799.

Lu, Y, Zhang, Z, Wang, H \& Wang, Y 2021, 'Toward efficient single-atom catalysts for renewable fuels and chemicals production from biomass and $\mathrm{CO} 2$ ', Applied Catalysis B: Environmental, Elsevier BV, pp. 120162. doi: 10.1016/j.apcatb.2021.120162.

Näzelius, IL, Boström, D, Boman, C, Hedman, H, Samuelsson, R \& Öhman, M 2013, 'Influence of peat addition to woody biomass pellets on slagging characteristics during combustion', Energy and Fuels, vol. 27, no. 7, pp. 3997-4006. doi: 10.1021/ef400366d.

Neh, A 2020, 'Agricultural Waste Management System [AWMS] in Malaysian', Open Access Journal of Waste Management \& Xenobiotics, vol. 3, no. 2, pp. 1-2. doi: 10.23880/oajwx-16000140.

O'Kelly, BC 2015, 'Drying temperature and water contentstrength correlations', vol. 1, no. 2, pp. 81-95. doi: 10.1680/ENVGEO.13.00016.

Syakirah, W, Osman, M, Ab Kadir, MZA \& Verayiah, R 2019, 'The potential and status of renewable energy development in Malaysia', Energies, vol. 2437, pp. 2-16. doi: 10.3390/en12122437.

Perry, KK 2020, 'For politics, people, or the planet? The political economy of fossil fuel reform, energy dependence and climate policy in Haiti', Energy Research and Social Science, vol. 63, pp. 101397. doi: 10.1016/j.erss.2019.101397.

Pradhan, P, Mahajani, SM \& Arora, A 2018, 'Production and utilization of fuel pellets from biomass: A review', Fuel Processing Technology, Elsevier BV, pp. 215-232. doi: 10.1016/j.fuproc.2018.09.021.

Putra, EI 2011, 'The effect of the precipitation pattern of the dry season on peat fire occurrence in the Mega Rice Project area, Central Kalimantan, Indonesia', Tropics, vol. 19, no. 4, pp. 145-156. doi: 10.3759/tropics.19.145.

Rahman, MN \& Wahid, MA 2021, 'Renewable-based zerocarbon fuels for the use of power generation: A case study in Malaysia supported by updated developments worldwide', Energy Reports, vol. 7, pp. 1986-2020. doi: 10.1016/j.egyr.2021.04.005.

Rena, SA, Chavan, D, Aiman, S \& Kumar, S 2020, 'Reducing greenhouse gas emission from waste landfill', in Encyclopedia of Renewable and Sustainable Materials, Elsevier, pp. 685-701. doi: 10.1016/b978-0-12-8035818.11022-7.

Sameeroddin, M, Deshmukh, MKG, Viswa, G \& Sattar, MA 2021, 'Renewable energy: Fuel from biomass, production of 
ethanol from various sustainable sources by fermentation process', Materials Today: Proceedings. doi: 10.1016/j.matpr.2021.01.746.

Schmidt, JJ 2020, 'Settler geology: Earth's deep history and the governance of in situ oil spills in Alberta', Political Geography, vol. 78, pp. 102132. doi: 10.1016/j.polgeo.2019.102132.

Sharma, HB, Sarmah, AK \& Dubey, B 2020, 'Hydrothermal carbonization of renewable waste biomass for solid biofuel production: A discussion on process mechanism, the influence of process parameters, environmental performance and fuel properties of hydrochar', Renewable and Sustainable Energy Reviews, Elsevier Ltd, pp. 109761. doi: 10.1016/j.rser.2020.109761.

Speight, JG 2020, 'Thermodynamics of water', in Natural Water Remediation, Elsevier, pp. 131-163. doi: 10.1016/b978-0-12-803810-9.00004-8.

Verdolini, E, Vona, F \& Popp, D 2018, 'Bridging the gap: Do fast-reacting fossil technologies facilitate renewable energy diffusion?', Energy Policy, vol. 116, pp. 242-256. doi: 10.1016/j.enpol.2018.01.058.

Wang, Q, Yin, S \& Ni, J 2021, 'The effects of n-pentanol, di-nbutyl ether (DBE) and exhaust gas recirculation on performance and emissions in a compression ignition engine', Fuel, vol. 284, pp. 118961. doi: 10.1016/j.fuel.2020.118961. 